\title{
Women with Methylenetetrahydrofolate Reductase Gene Polymorphism and the Need for Proper Periconceptional Folate Supplementation
}

\author{
Maureen Sullivan, Tiffany Murray and Haregewein Assefa \\ Touro College of Pharmacy, 230 West $125^{\text {th }}$ Street, New York, NY 10027, USA
}

\begin{abstract}
Maternal folate supplementation is critical for fetal development. Women with MTHFR (methylenetetrahydrofolate reductase) gene polymorphisms may not be getting the proper folate form to support fetal development. The objectives of this review were to: (1) undertake a comprehensive review on the association of MTHFR polymorphisms with the risk for various congenital diseases and other adverse pregnancy outcomes, (2) assess the efficacy and safety of current folic acid and other supplementations in women with the MTHFR polymorphism, and (3) provide guidance on the appropriate supplementation for women of childbearing potential with the MTHFR gene polymorphism in order to decrease these adverse pregnancy outcomes. Our assessments show that women with MTHFR gene polymorphism cannot efficiently convert folic acid to L-5-methyl-tetrahydofolate, the predominant active form of folic acid, due to reduced MTHFR enzymatic activity. L-5-methyl-tetrahydrofolate is currently commercially available under several brand names. Based on our comprehensive review and knowledge of the biochemistry of the folates, we recommend that L-5-methyltetrahydrofolate be given in combination with folic acid to women with MTHFR polymorphism that are pregnant or planning to become pregnant. Further study is needed to determine the optimal dose.
\end{abstract}

Key words: MTHFR (methylenetetrahydrofolate reductase) polymorphisms, maternal health, folic acid, birth defects, pregnancy outcomes, homocysteine, L-5-methlyl-THF (L-5-methytetrahydrofolate).

\section{Introduction}

Low folate status is a known risk factor for adverse pregnancy and fetal outcomes such as neural tube defects. The WHO (world health organization) has recently established a guideline on the optimal red blood cell folate levels in women of childbearing potential in order to prevent NTDs (neural tube defects) $[1,2]$. Synthetic folic acid, available in supplement form is currently the standard intervention for women who are pregnant or planning to become pregnant. The US (United States) Preventive Services Task Force and American Academy of Family Physicians recommend that all women of childbearing age or women planning to be pregnant take $0.4-0.8 \mathrm{mg} / \mathrm{day}$ of folic acid as a

Corresponding author: Haregewein Assefa, Ph.D., R.Ph., associate professor, research field: discovery and safe use of dietary supplements, natural products and pharmaceuticals. E-mail: Haregewein.Assefa@touro.edu. supplement [3]. Higher doses of folic acid are recommended for women with an increased risk for having NTD affected pregnancy. However, people with certain genetic single nucleotide polymorphisms (e.g. methylenetetrahydrofolate reductase gene polymorphism) cannot fully covert synthetic folic acid into the active forms and therefore may not fully benefit from this supplementation $[4,5]$. Although the US Preventive Services Task Force has listed mutations in folate-related enzymes as one of the risk factors for NTDs and the WHO guideline has documented that MTHFR (methylenetetrahydrofolate reductase) gene polymorphism is associated with low folate levels, there is no guideline on folate supplementation specific to women of reproductive age with MTHFR gene polymorphisms. The purpose of this manuscript is to: 1) give an overview of folic acid and other folates and how the human body utilizes 
them, 2) undertake a comprehensive review on the association of MTHFR gene polymorphisms with the risk for various congenital diseases and other adverse pregnancy outcomes, 3) examine the efficacy of current folic acid and other supplementations in women with the MTHFR polymorphism, and 4) provide guidance on the appropriate supplementation in order to decrease congenital diseases and adverse pregnancy outcomes in women of childbearing potential and expecting mothers with the MTHFR gene polymorphism.

\subsection{Folate and Folic Acid: What Is the Difference?}

Folates are essential in biochemical reactions and serve as cofactors in processes that involve one-carbon transfer [6]. Folate is a general name given to structurally-related water soluble vitamins (also known as vitamin B9, Fig. 1) and includes THF (tetrahydrofolate), 5-10-methylene-THF (5, 10-methylenetetrahydrofolate), L-5-methyl-THF (L-5-methyltetrahydrofolate) and 10-formyl-THF (10-formyltetrahydrofolate). The 10-formyl-THF and 5-10-methylene-THF are used in the synthesis of purines and pyrimidines, respectively while the L-5-methyl-THF serves as a methyl donor in the conversion of homocysteine to methionine [7, 8]. Folic acid is a synthetic form of folate and is the most oxidized form. Since natural dietary folates are unstable and found to lose activity during harvesting, storage and processing [9], a synthetic version (folic acid) was once essential. Folic acid is more stable than naturally occurring dietary folates and therefore the main form used in vitamin supplements and in food fortification $[9,10]$. In the body, folic acid is converted by the catalytic action of dihydrofolate reductase to THF, which is used as a precursor for the formation of the active folates; 5-10-methylene-THF, L-5-methyl-THF and 10-formyl-THF. Natural dietary and cellular folates exist as polyglutamates (where $\mathrm{R}=>$ 1 glutamic acid residue, see Fig. 1) [9]. The polyglutamate forms have low absorption, therefore dietary folates undergo deconjugation to the monoglutamate form ( $\mathrm{R}=\mathrm{OH}$, Fig. 1) in the gut before absorption. On the other hand, synthetic folic acid is available only as monoglutamate and thus has higher bioavailability than the natural dietary folates.<smiles>[R]C(=O)CC[C@H](NC(=O)c1ccc(NC[C@H]2CNc3nc(N)nc(O)c3N2)cc1)C(=O)O</smiles><smiles>[R]C(=O)CCCNC(=O)c1ccc(N(C)C[C@@H]2CNc3nc(N)nc(O)c3N2)cc1</smiles>

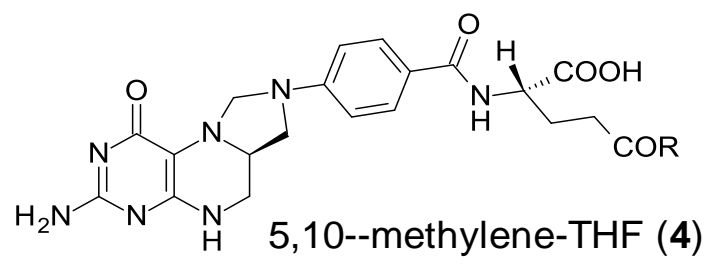<smiles>[R]C(=O)CC[C@H](NC(=O)c1ccc(NC[C@H]2CNc3nc(N)nc(O)c3N2C)cc1)C(=O)O</smiles>

Fig. 1 Folic acid and the most common natural folates: monoglutamate forms, $R=O H$; polyglutamatate forms, $R=>1$ glutamic acid residues. 
1.2 Methylenetetrahydrofolate Reductase Gene Polymorphisms and Its Effects on Folate Metabolism and Folate-Based Biochemical Reactions

The MTHFR (methylenetetrahydrofolate reductase) gene encodes MTHFR, an enzyme that catalyzes the synthesis of L-5-methyl-THF from 5-10-methylene-THF [11]. The normal MTHFR allele encodes a fully functional MTHFR enzyme. Many genetic SNPs (single nucleotide polymorphisms) of the MTHFR gene have been identified, but the MTHFR C677T and A1298C variations are the most common [12-15]. Each individual has two copies of the MTFHR gene, one inherited from each parent. An individual can either be heterozygous (SNP in one copy of the gene) or homozygous (SNP in both copies of the genes) in the MTHFR gene. It is also possible for some individuals to present with a compounded heterozygous polymorphism, which is one SNP located at two different parts of the MTHFR gene (MTHFR 677CT /1298AC) [16, 17].

The C677T polymorphism is a missense mutation on exon 4. Cytosine which is normally found at position 677 is replaced with a thymine residue and this results in valine being substituted for alanine $[12,18]$. The homozygous polymorphism (C677TT) reduces enzymatic activity by $70 \%$, while the heterozygous polymorphism (C677CT) results in approximately $35 \%$ reduction of enzymatic activity [7]. The A1298C polymorphism results from a single nucleotide change at exon 7 where adenosine is replaced by cytosine and as a result glutamate is substituted for alanine. The homozygous polymorphism (A1298CC) results in about $40 \%$ reduction in enzymatic activity while the compounded heterozygous polymorphism (C677CT/A1298AC) has been shown to decrease enzymatic activity by $40 \%-50 \%$ [4]. Hence, MTHFR gene polymorphism leads to reduction in enzyme activity, which results in lower levels of L-5-methyl-THF.

Since L-5-methyl-THF serves as a methyl donor in the conversion of homocysteine to methionine, deficiencies in the enzymatic activity of MTHFR leads to elevated homocysteine and low methionine levels. This is important because further biochemical reactions are disrupted as methionine is conjugated with adenosine to form SAMe (S-adenosylmethionine). SAMe is then used as a methyl donor in the methylation of lipids, hormones, nucleic acids (DNA and RNA) and myelin basic proteins. In summary, MTHFR gene polymorphism can cause low methionine levels, which may lead to low SAMe levels and improper methylation of DNA and other biomolecules [15, 19-22].

\subsection{Populations Affected}

Both C677T and A1298C MTHFR gene polymorphisms have shown variation within different ethnic groups. A HuGE review by Botto and Yang published in 2000 reported on the MTHFR gene polymorphisms by ethnicity and geographic area [23]. According to this review, Hispanics seem to have the highest rate of C677T polymorphisms with up 21\% reportedly homozygous (677TT). European whites were second with rates from 8-18\%. Ireland and Britain have had high rates of neural tube defects and their reported rate of C677TT homozygous polymorphism was $11-13 \%$. Asians were next with reports of about $11 \%$ frequency of C677TT homozygous polymorphism and blacks were lowest at $1 \%-2 \%$. The A1298C polymorphism is not as well documented as the C677T polymorphism. The A1298CC homozygous polymorphism was found to be approximately $9 \%$ based on studies in the Netherlands and Canada. The compounded heterozygous populations (C677T/A1298C) were estimated to be about $15 \%$ in Canada, $17 \%$ in US and $20 \%$ in Netherlands [23]. Esfahani et al studied the prevalence of MTHFR polymorphism in different ethnic groups and also found the 677TT to be highest in Mexican woman and lowest in African American women. This was also the finding for the compounded heterozygous genotype 
with Mexican and white women having the highest prevalence and Asian and African American women, the lowest. The study also found the A1298CC homozygous polymorphism to be highest in white women [24].

\subsection{Folate Status in Pregnancy}

Maternal folate metabolism and levels plays an important role in fetal development and having a healthy baby $[12,25,26]$. Many studies have examined the association of folate metabolism and levels with fetal and maternal health. Pregnant women are at high risk for folate deficiency due to the increase of folate requirements for fetal growth [19]. Reduced MTHFR enzymatic activity can cause low serum folate levels, elevated homocysteine levels and decrease methylation of DNA, proteins, lipids and hormones [16, 19, 27]. Homocysteine levels less than $13 \mu \mathrm{mol} / \mathrm{L}$ is normal, levels between 13 to $60 \mu \mathrm{mol} / \mathrm{L}$ is moderate, and $>60$ $\mu \mathrm{mol} / \mathrm{L}$ is considered severely elevated [16]. High homocysteine levels and folate deficiency could affect development of ovarian follicle, fertilization, as well as formation and development of the embryo [21]. Due to the inability to properly process folate, pregnant woman with MTHFR gene polymorphisms have an increased risk for many deleterious defects, such as having a baby with NTDs (neural tube defects), congenital heart disease and cardiac septal effects, down syndrome, cleft palate, omphalocele, attention deficit hyperactivity disorder and low birth weight as well as pregnancy loss, preeclampsia, pregnancy-associated osteoporosis and susceptibility to arsenic toxicity in pregnancy.

\section{Association of MTHFR Gene Polymorphism with Congenital Diseases and Other Adverse Pregnancy Outcomes}

\subsection{Neural Tube Defects}

NTDs (Neural tube defects) are a group of severe, disabling and deadly congenital disorders of the nervous system, arising from incomplete neural tube closure during early stages of pregnancy [28-30]. Anencephaly, SB (spina bifida), encephalocele, craniorachischisis and iniencephaly are the most common [31-33]. There are several types of SB but MM (myelomeningocele) commonly accounts for $90 \%$ of cases [34]. Most infants with NTDs usually die within days after birth or struggle with lifelong disabilities [29, 32, 34, 35]. The incidence of NTDs ranges from 1.0 to 10.0 per 1,000 births depending on the country [30]. In the US (United States), the prevalence of NTDs such as SB has decreased due to FDA (food and drug administration) mandated fortification of folic acid in enriched flours and grain products $[34,35]$. After fortification, SB in the US has decreased by approximately $22.9 \%$ from 2.62 to 2.02 per 10,000 births [36]. Although this has been effective, still 2,500 live births are affected by NTDs every year [32].

NTDs occur more frequently in Irish and Mexican populations compared to other Caucasians and Asians $[34,37]$. Other studies have also reported high prevalence in China [27]. The pathogenesis of NTDs is unknown and is caused by multiple factors such as genetics, nutritional deficiencies, and environmental determinants [29, 30]. Several studies have found positive association between the common MTHFR gene C677T polymorphism and risk of NTDs. The MTHFR gene 677TT genotype has been associated with a 4-fold increase risk of having a child with a NTD [38]. Interestingly, to date there are few studies that have extensively investigated the association between A1298C polymorphism and NTDs [39]. MTHFR gene C677T and A1298C polymorphisms result in decreased MTHFR enzymatic activity, which increases homocysteine levels and DNA hypomethylation [27, 40].

A case control study in Setif, Algeria found higher homocysteine levels in MTHFR 677TT homozygous mothers with spina bifida children than in mothers of healthy children $(P=0.06)$ [38]. Although this is not statistically significant the $P$-value is close to 0.05 . The 
same study also found an increased risk of NTDs in the elevated homocysteine mothers $(24 \%)$ versus control (4.9\%, $P=0.046$ ) [38]. These observations therefore support the hypothesis that elevated homocysteine levels are commonly found in mothers with MTHFR 677TT genotype, which indicates an increased risk of having a child with a NTD. A study conducted in Mexico examining the risk of anencephaly in association to folate, vitamin B12, homocysteine and MTHFR gene polymorphism reported that mothers with MTHFR 677TT genotype of anencephaly children had significantly lower serum folate levels $(8.2 \mathrm{ng} / \mathrm{mL})$ compared with mothers of healthy controls $(14.1 \mathrm{ng} / \mathrm{mL}$, $P=0.004$ ) [37]. A review conducted by N. Greene et al. also examined several studies that investigated the association of MTHFR gene polymorphisms and NTDs [41]. Pooled results from the studies demonstrated that MTHFR 677TT genotype was strongly associated with NTDs and there was no significant association between the A1298C polymorphism and risk of NTDs. Thus, mothers with MTHFR gene C677TT homozygous polymorphisms seem to be more at risk of having a child with NTDs compared to the other genotypes. However, a study in a Turkish population showed that MTHFR gene A1298C polymorphism might be associated with development of NTDs [39].

Although the exact mechanism is not known, research indicates that global DNA hypomethylation in fetal brain is associated with the pathogenesis of NTDs. DNA hypomethylation can alter normal repression or expression of genes during fetal development [42]. Very few epidemiological studies have investigated the association of DNA hypomethylation and risk of NTDs. A case control study done in China, found positive association between DNA hypomethylation in fetal brain tissue and risk of NTD affected pregnancies [27]. This study reported that out of the 65 NTD affected embryos (case), 8 cases resulted in craniorachischisis, 16 with anencephaly and open spina bifida, 14 with encephalocele, 23 with open spina bifida and four fetuses with spina bifida occulta. After stratification, the study found that MTHFR 677CT heterozygous and MTHFR 677 TT homozygous cases have lower DNA methylation levels compared to healthy control fetuses [27]. The study also found that the 677CC genotype cases had similar DNA methylation levels to that of the controls. Another case-control study conducted in two populations (Dutch Caucasians and Mexican-Americans in Texas) found significant association between hypomethylation and the risk of NTD in fetuses and very young children in the Dutch Caucasian study group but not in the Mexican-American study group [40]. The study found an absolute decrease of MTHFR DNA methylation by $0.33 \%$ in the Dutch Caucasian children with SB compared to controls $(P=0.001)$ [40]. Therefore, more epidemiological studies need to be conducted to better understand the association between impaired DNA methylation and risk of NTDs in humans.

\subsection{Congenital Heart Disease}

CHD (congenital heart defects) are common birth defects that often result from abnormal development of the heart during the first 6 weeks of pregnancy $[43,44]$. CHD is one of the major causes of infant death and illnesses [45]. Heart diseases in infants mainly include ASD (atrial septal defect), VSD (ventricular septal defect), PDA (patent ductus arteriosus), and other types. The majority of CHDs are affected by both genetic and environmental factors.

In recent studies, plasma homocysteine level has been shown to be elevated in CHD infants, which might be a possible risk factor for CSD (cardiac septal defects). A genetic variance in MTHFR is one possible cause of elevated plasma homocysteine. The impaired ability to process folate leads to the inability to convert homocysteine to methionine. Several theories exist for the mechanism by which elevated homocystiene levels can lead to CHD. One study suggested that high concentration of homocysteine was found to induce electrical remodeling of ion channels in human atrial cells that include potassium channels. The remodeling 
of potassium currents has been hypothesized to induce cardiac arrhythmias [46]. Other studies indicated that hyperhomocystenimia causes interstitial and perivascular fibrosis resulting in increased myocardial stiffness, thereby affecting the pump function of the myocardium, which then causes heart failure [47].

Knowing that a genetic variance in the MTHFR gene can lead to elevated homocysteine levels, several studies have examined the direct association between MTHFR gene C677T and A1298C polymorphism and the development of CHD in infants and children. Another case control study conducted in China that investigated mothers of 57 children with congenital heart disease of ASD, PDA or both versus 104 control mothers, found that maternal MTHFR gene C677TT homozygous polymorphism was associated with high risk of PDA and ASD in offsprings [48]. A study conducted in Canada looked at the relationship of A1298CC homozygous polymorphism and congenital heart diseases of ventricular septal defect and aortic valve stenosis. It was demonstrated that maternal MTHFR 1298AC heterozygous genotype was associated with increased risk for aortic valve stenosis. However, this study also reported mixed results on negative association between 677TT genotype and congenital heart defects [49].

CHD is caused by multiple factors including both genetic and nongenetic factors. The pathophysiology of CHD is complex and a single factor such as the MTHFR gene polymorphism cannot explain the whole cause. Although elevated homocysteinemia is observed in populations with congenital heart diseases such as cardiac septal defects, elevated homocysteine level is not the only factor contributing to the pathophysiology. Further studies need to be conducted in women with MTHFR gene polymorphism and elevated homocysteine to determine how proper folate supplementation can affect maternal health and the health of the offspring in terms of congenital heart disease.

\subsection{Down Syndrome}

DS (down syndrome) also known as trisomy 21 is a chromosomal disease that is associated with growth and mental retardation $[50,51]$. DS results from an over-expression of three extra copies of the gene on chromosome 21 causing failure of normal chromosomal separation during meiosis [21, 51, 52]. DS affects approximately 1 in 1000 to 1100 live births worldwide and 1 out of every 700 newborns in the US $[53,54]$. An important risk factor for DS is advanced maternal age at the time of conception [51, 52]. Women who are 35 years or older are more at an increased risk of having a child with DS, however DS children have been born to younger mothers [55-58]. Studies have shown that mothers of children with DS have abnormal folate metabolism, high homocysteine and hypomethylation similar to NTDs, which result in abnormal gene expression and chromosomal segregation [20, 50, 53, 59].

Zampieri et al. investigated the influence of 12 genetic polymorphisms including the MTHR C677T and A1298C on folate metabolism and risk of DS. The MTHFR gene homozygous C677TT or heterozygous C677CT polymorphisms was associated with the risk of having a DS child ( $\mathrm{p}$ value 0.0005 ). This study confirmed low serum folate levels in DS mothers (12.2 $\mathrm{ng} / \mathrm{mL})$ compared to control group $(14.6 \mathrm{ng} / \mathrm{mL})(P=$ 0.028 ) as a maternal risk factor for a child's development of DS [58]. With respect to the impact of MTHFR gene polymorphism and folate levels, folate concentrations below the 25th percentile were associated with presence of either MTHR gene C677CT or C677TT polymorphism. This study hypothesized that the increased maternal risk of DS may be due to the reduction in enzymatic activity of MTHFR [58]. Rai et al [56] conducted a study in eastern state of India, which genotyped 312 mothers for C677T and A1298C polymorphisms. The study showed an association between both the C677T and A1298C polymorphisms and maternal risk of having DS children. The homozygous 677TT genotype was 
7.6 times higher in the case study mothers compared to controls. The distribution of C677T genotypes according to age groups revealed that all 12 homozygous 677TT mothers were aged less than 31 years among the total of 101 mothers aged less than 31 years. The frequency of homozygous A1298CC polymorphism was higher in DS case mothers (22) versus control (5) $(\mathrm{P}=0.008)$. All of the young mothers with homozygous 677TT genotype had either a first or second child born with DS. The study revealed the frequencies of the $1298 \mathrm{C}$ allele and homozygous $1298 \mathrm{CC}$ genotype to be higher in case mothers (46.6\%, $24.1 \%)$ compared to controls $(33.5 \%, 7.1 \%)$, respectively. (p value $0.003,0.008$ ) [56]. Like the previous study, Rai et al. concluded that polymorphisms in MTHR gene results in hypomethylation of DNA that could affect various cellular functions, such as DNA repair, replication, gene expression and chromatin conformation, leading to disease conditions. Other epidemiological studies have also found strong association between the MTHFR 677T allele and risk of DS [17, 20, 52, 59-62]. Contrary to the above studies, others have shown that there is no association between MTHR polymorphisms and risk of DS, therefore further studies are necessary [63-65].

\subsection{Cleft Palate}

$\mathrm{CL} / \mathrm{P}$ (cleft lip with or without cleft palate) is birth defect, which happens early during pregnancy where baby's lip or mouth does not form properly. During the early pregnancy, a baby's head forms by the joining of body tissue from each side of the head in the center. The lip is formed during the fourth and seventh week, and the roof of the mouth between the sixth and ninth week of pregnancy. If the lip tissues and/or palate tissues do not join completely, it results in an opening, which is cleft lip and/or cleft palate. According to CDC, each year in the United States, about 2,650 babies are born with a cleft palate and 4,440 babies are born with a cleft lip with or without cleft palate [66]. Both genetic and environmental factors are known to play a role in the development of CL/P and many studies have been conducted to verify the association between two functional polymorphisms - C677T and A1298C - in the MTHFR gene and an increased risk of CL/P. Studies on the association of MTHFR gene polymorphism with $\mathrm{CL} / \mathrm{P}$ were performed in different region of the world to find the prevalence among subjects with $\mathrm{CL} / \mathrm{P}$. In many studies, it has been proposed that low periconceptional folate intake increases the risk of CL/P in offspring, and this risk is even more pronounced in mothers with homozygous MTHFR 677TT or 1298CC genotypes. In a study performed in 153 patients with nonsyndromic oral clefts and 205 control subjects genotyped for 176 different types of gene SNPs, MTHFR gene polymorphism showed evidence of association with CL/P [67]. There was a statistically significant difference between genotype frequencies of MTHFR C677T polymorphisms in non-syndromic CL/P cases compared with controls [68]. These and similar studies were performed in California, Brazil, Turkey, South America, Germany, Poland, Paris, Korea, China, Brazil, European and Northern Venezuela population samples. MTHFR gene A1298C locus was analyzed and shown positive and negative association with the cleft lip and palate [15, 69-71]. Despite the association between MTHFR C677T polymorphism and CL/P, there still needs more studies to be performed to indicate if the MTHFR gene polymorphism is the independent marker for the CL/P [72-74].

\subsection{Other Congenital Disease Sand Adverse Pregnancy} Outcomes

The MTHFR gene polymorphisms and mutation have also been found to be associated with a number of other congenital diseases and adverse pregnancy outcomes. A recent case report from the New England Journal of Medicine describes a boy with microcephaly and episodic cyanosis. After a very long differential diagnosis the boy was finally diagnosed at 10 months 
with severe MTHFR deficiency. The boy was treated with folinic acid (5-formyl-tetrahydrofolic acid) and other active forms of the B vitamins, which resulted in clinical and symptomatic improvement. The authors of this case identified two novel mutations in the MTHFR gene that put the patient at risk of developing microcephaly and episodic cyanosis [75]. Other studies have been conducted to extensively examine the association of MTHFR polymorphisms and other congenital diseases such as omphalocele, attention deficit hyperactivity disorder, and microcephaly. A study conducted on genetic information from all newborn births in New York from 1998-1999, found significant association between MTHFR 677T allele and risk of omphalocele [76]. Other studies have also shown strong association between risk of omphalocele and MTHFR C677Tpolymorphism [77].

Homocysteine concentration has been reported to be positively associated with the risk of pregnancy complications such as low birth weight, increased incidence of pregnancy loss, preeclampsia, intrauterine growth retardation, and placental infarction [78]. A prospective cohort study, which investigated the DNA of pregnant women with complications (intrauterine fetal death, preeclampsia, preterm delivery, and small for gestational age infants) showed significantly higher frequency of MTHFR gene C677T polymorphism compared to control subjects. This study also showed higher frequencies of homozygous 677TT allele than the heterozygous 677CT allele. In a subgroup analysis, statistically significant increase in MTHFR C677T polymorphism was observed in women with small for gestational age newborns [78]. In a meta-analysis study performed in Caucasian and East Asian populations, the MTHFR C677T polymorphism was associated with a risk of preeclampsia [79]. In another study performed in India, the data showed that MTHFR A1298C heterozygous or homozygous genotypes significantly increased the risk of recurrent pregnancy loss [80].

In a Mendelian randomization study conducted in Seoul, Korea, birth weight significantly differed in relation to MTHFR C677T genotype. The MTHFR homozygous 677TT allele showed lower birth weights than the normal $677 \mathrm{CC}$ allele. Birth weight also decreased as maternal homocysteine level increased [81]. According to another study conducted in Mexico City, birth weight was $4 \mathrm{~g}$ higher for every $100 \mu \mathrm{g} /$ day increase in folate intake; however, neither maternal nor infant MTHFR genotype was associated with differences of infant weight at birth [82]. A similar study conducted in the United Kingdom also showed no significant relationship between MTHFR polymorphism and low birth weight [83]. Different studies demonstrated mixed results on association of MTHFR C677T and/or A1298C polymorphism in pregnancy outcomes $[80,84,85]$. Thus, it is suggested that more studies with large samples be conducted to be more conclusive.

\section{Supplementation}

\subsection{Folic Acid}

Adequate folate levels are paramount in pregnancy for proper fetal development and maternal health. There is a large body of evidence supporting the protective effects of folic acid in preventing NTDs and other adverse pregnancy outcomes such as miscarriages and preeclampsia [86]. Folate deficiency can result from poor dietary intake or failed intracellular retention of folate and leads to elevated homocysteine levels that are associated with various congenital disorders such as NTDs, specifically spina bifida and anencephaly [17]. Although the underlying mechanism by which folic acid prevents NTDs is widely unknown, many epidemiological studies have shown that supplementation of folic acid during the periconception period decreases the risk and recurrence of NTD-affected pregnancies by approximately 4 folds [13]. A four year epidemiological study showed a reduction of 50\%-70\% spina bifida cases and 25\%-50\% anencephaly cases with supplementation of $5 \mathrm{mg} /$ week folic acid [87]. It is generally recommended that women of childbearing 
age consume supplements containing at least 0.4-0.8 $\mathrm{mg}$ of folic acid daily to reduce the risk of NTDs. However, most experts recommend higher doses of folic acid supplements for women at intermediate to high risk of having a child with a NTDs. Currently, the US Preventive Services Task Force and American Academy of Family Physicians recommend that all women of childbearing age or women planning to be pregnant take $0.4-0.8 \mathrm{mg} /$ day of folic acid as a supplement. This recommendation does not apply to women who have had previous NTD affected pregnancy and women on some antiseizure drugs [3]. Certain antiseizure drugs are known to cause folate deficiency and higher dose of folic acid is recommended for all women of childbearing age and pregnant women [88]. Although there has not been any study that determined the optimal dose of folic acid for women on antiseizure drugs, it is usually recommended that women of childbearing potential take $1 \mathrm{mg} /$ day of folic acid and the dose be increased to $4 \mathrm{mg}$ /day following conception [88]. The American College of Obstetricians and Gynecologists recommends a folic acid supplement of $0.4 \mathrm{mg} / \mathrm{day}$ for women at low risk of NTDs and $4 \mathrm{mg} /$ day for women at high risk of NTDs or who have had a previous pregnancy with an NTD [89].

While research has indicated that MTHFR gene polymorphism is associated with an increased risk for neural tube defect, there is no guideline on folic acid supplementation specific to women with MTHFR gene polymorphism. However, the US Preventive Services Task Force has listed mutations in folate-related enzymes as one of the risk factors for NTDs and by implication women with MTHFR gene polymorphism may need to take higher doses of folic acid [3]. MTHFR catalyzes the conversion of 5 , 10-methylene-THF to L-5-methyl-THF, one of the active forms of folic acid that is used as a one-carbon source in the synthesis of methionine from homocysteine. MTHFR gene polymorphism reduces levels of L-5-methyl-THF and increases homocysteine levels [90]. Therefore, plasma homocysteine level is used as a sensitive indicator of folate status and MTHFR function. Plasma homocysteine levels can also increase due to vitamin B6 or B12 deficiency. Thus, B12 and B6 deficiency should be ruled out prior to utilizing plasma homocysteine level as a biomarker for folate status and MTHFR function.

The effects of folic acid $(0.4 \mathrm{mg} /$ day or $0.8 \mathrm{mg} /$ day $)$ on homocysteine levels in Chinese hypertensive patients with heterozygous C677CT or homozygous C677TT polymorphism were assessed. This was done in a multicenter, randomized, double-blind control study. The results showed that homocysteine levels remain high in patients with homozygous C677TT polymorphism treated with either $0.4 \mathrm{mg} /$ day or 0.8 $\mathrm{mg} /$ day of folic acid as well as in patients with heterozygous C677CT polymorphism treated with 0.4 $\mathrm{mg} /$ day of folic acid [91]. In another large-scale population-based double blind trial, the effects of six months supplementation of different folic acid doses ( $0.1 \mathrm{mg} /$ day, $0.4 \mathrm{mg} /$ day, $4 \mathrm{mg} / \mathrm{day}, 4 \mathrm{mg} /$ week) on plasma homocysteine levels, plasma folate levels and red blood cell folate levels were evaluated [92]. The study showed that folic acid dose of $0.1 \mathrm{mg} /$ day and 4 $\mathrm{mg} /$ week given for 6 months did not reduce the high homocysteine levels in those women with MTHFR homozygous 677TT genotype. Even with the high dose of $4 \mathrm{mg} /$ day folic acid supplementation, women with MTHFR 677TT genotype showed higher plasma homocysteine levels as well as lower plasma and RBC folate levels compared to women with the MTHFR normal 677CC genotype [92]. In animal model of severe MTHFR deficiency, folic acid failed to decrease mortality while L-5-methyl-THF reduced mortality by $31 \%$. Based on these and other studies, high dose of folic acid alone may not be sufficient as a supplement for women with MTHFR polymorphism and people with severe MTHFR deficiency.

Although folic acid is generally considered safe, there are several studies that raise concerns regarding its safety. Folic acid is the most oxidized form of the 
folates and is believed to be metabolized in the intestine and the liver to tetrahydrofolic acid and subsequently to 5-L-methyl-THF. However, a study showed the presence of unmetabolized folic acid in the blood and its level was dose-dependent and accumulated with repeated exposure [93]. The unmetabolized folic acid was associated with reduced natural cell cytotoxicity and this effect was greater with increased levels of unmetabolized folic acid [94]. High folic acid intake was also found to be associated with cognitive decline in older people [95]. In addition, there are several reports on the association of folic acid supplement with certain cancers such as prostate and colorectal cancers [96-98]. High dose folic acid may also mask Vitamin B12 deficiency by correcting macrocytic anemia [99]. The effect of B12 deficiency on RBC (macrocytic anemia) can be easily diagnosed while the neurological effects may not be identified until after the disease has progressed. Vitamin B12 mainly plays a role in the regeneration of THF and the effect of B12 deficiency on RBC can be prevented by administering higher dose of folic acid.

\subsection{L-5-Methyltetrahydrofolate}

L-5-methyl-THF (L-5-Methyltetrahydrofolate) is the predominant active form of folic acid in the plasma and in red blood cells. It is also naturally present in dietary sources mostly as polyglutamates [9]. The calcium salt of L-5-methyl-THF (L-5-methyl-THF calcium), which is also known as levomefolate calcium is available as a dietary supplement and is marketed under the brand names Deplin [100] and Metafolin. It is also available in combination with oral contraceptives as Safyral and Beyaz. Each Safyral and Beyaz tablet contains $0.451 \mathrm{mg}$ of levomefolate calcium along with $3 \mathrm{mg}$ of drospirenone. The difference between Safyral and Beyaz is in the amount of ethylene estradiol. Both Safyral and Beyaz were approved by the FDA in 2010 and the levomefolate calcium in the contraceptive pills was intended to reduce the risk of NTD in a pregnancy conceived while taking the contraceptive or soon after discontinuation of the contraceptive. The European Food Safety Authority Panel also evaluated L-5-methyl-THF calcium in 2004 and concluded that there is no safety concern when it is used as a source of folate in foods and food supplements with a tolerable upper level of 1mg/adult/day [101]. In 2013, the European Food Safety Authority Panel similarly gave a scientific opinion on the safety and bioavailability of the glucosamine salt of L-5-methyl-THF (L-5-methyl-THF glucosamine) in response to a request from the European commission. Based on a comparative crossover bioavailability study in human volunteers, the panel concluded that L-5-methyl-THF glucosamine has similar bioavailability to that of L-5-methyl-THF calcium [102]. The panel also came to the conclusion that there was no safety concern regarding the genotoxicity of L-5-methyl-THF glucosamine.

The approval of L-5-methyl-THF calcium as part of a contraceptive by the US FDA and the scientific comments by the European Food Safety Authority ascertain the safety of L-5-methyl-THF. A number of pharmacokinetic and pharmacodynamic studies have indicated that L-5-methyl-THF has similar bioavailability to that of folic acid and it is at least as effective as folic acid in correcting folate status and decreasing homocysteine levels [103-106]. An epidemiological study compared the effects of a prenatal supplement containing $1.13 \mathrm{mg}$ of L-5-methyl-THF plus folic acid $0.4 \mathrm{mg}$ with standard PNV (prenatal vitamins) containing 0.8 to $1 \mathrm{mg}$ of folic acid alone on decreasing the rate of anemia in pregnant women. This study found that fewer women developed anemia in the prenatal supplement containing L-5-methyl-THF and folic acid compared with the standard treatment of PNV [86]. In a randomized double-blind study involving healthy women of childbearing potential, steady-state plasma and RBC folate levels were compared following administration of oral contraceptives containing either $0.4 \mathrm{mg}$ of folic acid or $0.451 \mathrm{mg}$ of levomefolate calcium for 24 weeks 
[107]. The study results demonstrated that both plasma and $\mathrm{RBC}$ folate levels were slightly higher in the levomefolate group compared to the folic acid group during the treatment phase as well as during the 20 weeks following cessation of treatment [107]. Another randomized double-blind study that compared the effects of equimolar amounts of L-5-methyl-THF and folic acid on RBC folate levels demonstrated that L-5-methyl-THF is more effective than folic acid in correcting folate status [108]. In a randomized study comparing the effects of $0.4 \mathrm{mg}$ of folic acid and 0.412 $\mathrm{mg}$ of L-5-methyl-THF on the pharmacokinetics of folate, Prinz-Langenohl et al showed that total plasma folate levels and Cmax (the maximum folate concentration) were higher and Tmax (the time to peak) was shorter in women with homozygous 677TT genotype supplemented with L-5-methyl-THF than those supplemented with folic acid [109].

\subsection{Betaine}

Betaine is either obtained from diet or synthesized in the body from choline [110]. The recommended betaine intake is estimated at 0.5 to 3 grams per day [111-113]. Homocysteine is methylated to methionine with either betaine or L-5-methyl-THF as the methyl donor. Thus, betaine and L-5-methyl-THF are interchangeable sources of methyl group in the conversion of homocysteine to methionine [110]. The reaction that uses betaine as a methyl donor is catalyzed by the enzyme BHMT (betaine-homocysteine methyltransferase), which is located only in the liver and kidney [112, 114, 115]. In the liver, BHMT catalyzes up to $50 \%$ of homocysteine metabolism [112]. Therefore, BHMT regulates homocysteine levels in the liver. Epidemiological studies have indicated that dietary supplementation with betaine may reduce homocysteine levels in healthy volunteers and individuals with hyperhomocysteinemia [112, 114]. Studies have shown that treatment with betaine may reduce the risk of consequences of severe MTHFR deficiency [116]. A meta-analysis of 15 case reports and case series involving 35 patients investigated the effects of betaine on survival and psychomotor development in patients with severe MTHFR deficiency. The results indicated that all five patients who were treated with betaine early survived and had normal psychomotor development. On the other hand, the 11 patients that died were either not treated with betaine or their treatment was delayed. None of the remaining 19 survivors whose treatment was delayed had normal psychomotor development. A new born baby with MTHFR deficiency was treated with increasing doses of betaine for two years and the researchers reported that $6 \mathrm{~g}$ /day of betaine administered in six divided doses resulted in adequate control of homocysteine levels [117]. Although physical development was normal, language and motor developments were delayed by 3-6 months. This study concluded that early betaine treatment prevents mortality and allows normal psychomotor development in patients with severe MTHFR deficiency [116]. Holm and colleagues [118] reported that plasma betaine levels are inversely associated with plasma total homocysteine levels and this is more pronounced in those with C677TT homozygous polymorphism and low folate status, implying that betaine is an important methyl donor especially in those with low folate status and MTHFR polymorphism. All the studies indicated that betaine is an alternative methyl donor in those with MTHFR polymorphism and deficiency. Therefore, betaine can be used as add-on supplement for individuals with MTHFR polymorphism.

\section{Discussion}

This article presents a comprehensive review on the effects of MTHFR gene polymorphism on folate metabolism and its association with an increased risk for various congenital diseases and other adverse pregnancy outcomes. It also examines the pharmacodynamic effects and pharmacokinetic properties of several supplements that are used to 
prevent NTDs and other adverse outcomes related to folate deficiency or inept folate metabolism. Based on our assessment, we will provide a recommendation on the supplementation to women of childbearing potential with MTHFR gene polymorphism.

Folates are essential for proper fetal development and maternal health. The demand for folates increases during pregnancy, therefore folate supplementation is necessary. Natural dietary folates are unstable and degrade during harvesting, processing, and storage [9]. In addition, natural dietary folates exist as polyglutamates, which are less absorbable forms. Hence, natural dietary folates have to undergo deconjugation to monoglutamate forms in the gastrointestinal tract before absorption. As a result, natural dietary folates have low bioavailability [10]. Because of the low bioavailability and stability issues, the natural dietary source of folates may not be adequate during pregnancy when the demand for folates is higher. Folic acid, the synthetic and most oxidized form of the folates, is used as supplement and in food fortification due its stability and good bioavailability [10]. Numerous studies have shown that periconceptional folic acid supplementation decreases the recurrence of fetal neural tube defects (NTDs) [119, 120]. Neural tube closes three to four weeks postconception. Because the neural tube forms early in the pregnancy, at a time when women are not even aware of that they are pregnant, and half of the pregnancies in the USA are unplanned [119], it is recommended that all women of childbearing potential take folic acid supplementation. In general, the current folic acid recommendation is $0.4-0.8 \mathrm{mg} /$ day for all women of child bearing age who are low risk for having a fetus with NTD [3]. Higher doses of folic acid are recommended for women at higher risk for having an NTD affected pregnancy.

MTHFR gene polymorphism, particularly C677T and A1296C have been shown to be associated with an increased risk for NTDs and other deleterious pregnancy outcomes. Although mutations in folate metabolizing enzymes have been recognized as one of the risk factors for NTDs [3] and the WHO guideline on folate levels [2] has documented that MTHFR polymorphism is associated with low folate levels, there are no recommendations on folate supplementation specific to women with MTHFR polymorphism. However, since higher doses of folic acid is recommended for women at high risk for having NTD affected pregnancy, by implication women with MTHFR polymorphism may take high dose of folic acid. Homozygous C677TT and A1298CC polymorphism as well as compounded heterozygous polymorphism (C677CT/A1298AC) have been shown to decrease the enzymatic activity of the MTHFR by $40-70 \%[4,5,121]$. MTHFR is a key enzyme that catalyzes the synthesis of L-5-methyl-THF from folic acid. L-5-methyl-THF is the major active form of folates in the plasma and in red blood and serves as methyl donor in the synthesis of methionine from homocysteine.

Although current recommendations imply that women with MTHFR polymorphism may take high dose of folic acid, they may not benefit from high dose of folic acid and may even have detrimental effect on their health for a number of reasons. People with MTHFR polymorphism cannot convert folic acid to L-5-methyl-THF efficiently due to the reduced activity of the MTHFR enzyme. Therefore, giving more folic acid to process for an enzyme that is working at lower capacity appears inconsistent with the scientific bases. High dose of folic acid has also been found to mask B-12 deficiency [99] and has been associated with decreased immunity [94] as well as impaired cognition [95].

Currently, the stable form of L-5-methyl-THF is available as a calcium salt. L-5-methyl-THF calcium, which is also known as levomefolate calcium is commercially available under various proprietary names. Pharmacokinetic and pharmacodynamic studies have shown that the bioavailability of L-5-methyl-THF is similar to that of folic acid and it is at least as 
effective as folic acid in correcting folate status. However, in people with MTHFR polymorphism, L-5-methyl-THF has been shown to be more effective in correcting folate status and reducing homocysteine levels [109]. Our comprehensive literature study and understanding of the biochemistry of folates and folate-based biochemical reactions indicate that a combination of L-5-methyl-THF and folic acid would be a better choice for women of childbearing potential with MTHFR polymorphism. However, a study is needed to establish the optimal dose of L-5-methyl-THF. L-5-methyl-THF calcium is available in various strengths ranging from $0.4 \mathrm{mg}$ to $15 \mathrm{mg}$ of oral tablets or capsules. The FDA has approved oral contraceptives containing $0.451 \mathrm{mg}$ of L-5-methyl-THF calcium. The European Food Safety Authority Panel has also concluded that there is no safety concern when L-5-methyl-THF calcium is used as a supplement up to $1 \mathrm{mg} /$ adult/day [101]. Therefore, the safety of L-5-methyl-THF calcium at a dose greater than $1 \mathrm{mg} /$ day is unknown and requires studies. The synthesis of methionine from homocysteine uses either betaine or L-5-methyl-THF as a methyl donor. Consequently, studies have shown that supplementation with betaine reduces the risk of the consequence of MTHFR gene polymorphism or severe MTHFR deficiency. Therefore, betaine may be added to the folic acid supplement in women with MTHFR polymorphism. However, at this point we cannot recommend betaine in pregnant women due to a lack of safety studies.

\section{Conclusion}

MTHFR gene polymorphism is associated with an increased risk for a number of birth defects including NTDs as well as other adverse pregnancy outcomes. Because of the reduced MTHFR enzymatic activity, women with MTHFR gene polymorphism cannot get the full benefit from high dose of folic acid supplementation and even may have detrimental effect on their health. Women with a homozygous or compounded heterozygous polymorphism are at a higher risk of adverse pregnancy outcome due to the significant reduction in enzymatic activity. The stable form of the end product of MTHFR, L-5-methyl-THF is currently available. Pharmacokinetic studies have shown that the bioavailability of L-5-methyl-THF is similar to that of folic acid. Studies have also demonstrated that there is no safety concern when L-5-methyl-THF calcium is used up to $1 \mathrm{mg} /$ day and it is more effective than folic acid at correcting folate status in individuals with MTHFR gene polymorphism. Therefore, L-5-methyl-THF calcium should be given in combination with folic acid to women of childbearing potential with MTHFR gene polymorphism. However, study is needed to establish the optimal dose. L-5-methyl-THF calcium is marketed in various strengths ranging from $0.4 \mathrm{mg}$ to $15 \mathrm{mg}$ of oral tablets or capsules. The safety of L-5-methyl-THF at a dose greater than $1 \mathrm{mg}$ /day/adult is unknown. Thus, study is needed to determine the safety profile of L-5-methyl-THF at higher doses. Betaine and L-5-methyl-THF are interchangeable sources of methyl group in the biochemical conversion of homocysteine to methionine and alternatively betaine may be added to folic acid supplement for women with MTHFR polymorphism.

\section{References}

[1] Cordero, A. M., Crider, K. S., Rogers, L. M., Cannon, M. J., and Berry, R. J. 2015. "Optimal Serum and Red Blood Cell Folate Concentrations in Women of Reproductive age for Prevention of Neural Tube Defects: World Health Organization Guidelines." MMWR Morb. Mortal. Wkly. Rep. 64 (15): 421-3.

[2] WHO. 2015. "Guideline: Optimal Serum and Red Blood Cell Folate Concentrations in Women of Reproductive Age for Prevention of Neural Tube Defects." Geneva, Switzerland. Accessed: July 6, 2015. http://www.who.int/nutrition/publications/guidelines/opti malserum_rbc_womenrep_tubedefects/en/.

[3] U.S. Preventive Services Task Force. 2009. "Folic Acid for the Prevention of Neural Tube Defects: U.S. Preventive Services Task Force Recommendation Statement." Ann. Intern. Med. 150 (9): 626-31.

[4] Weisberg, I., Tran, P., Christensen, B., Sibani, S., and 
Rozen, R. 1998. “A Second Genetic Polymorphism in Methylenetetrahydrofolate reductase (MTHFR) Associated with Decreased Enzyme Activity." Mol. Genet. Metab. 64 (3): 169-72.

[5] Yousefian, E., Kardi, M. T., and Allahveisi, A. 2014. "Methylenetetrahydrofolate Reductase C677T and A1298C Polymorphism in Iranian Women with Idiopathic Recurrent Pregnancy Losses." Iran Red. Crescent. Med. J. 16 (7): e16763.

[6] Arinze, I. J. 2005. "Facilitating Understanding of the Purine Nucleotide Cycle and the One-Carbon Pool, Part II: Metabolism of the One-Carbon Pool." Biochem. Mol. Biol. Educ. 33 (4): 255-9.

[7] Fukuda, N., Hamajima, N., Wakai, K., and Suzuki, K. A. 2014. "Cross-Sectional Study to Find out the Relationship of Methylenetetrahydrofolate Reductase (MTHFR) C677T Genotype with Plasma Levels of Folate and Total homocysteine by daily folate intake in Japanese." J. Nutr. Sci. Vitaminol. 60 (4): 231-8.

[8] Barua, S., Kuizon, S., and Junaid, M. A. 2014. "Folic Acid Supplementation in Pregnancy and Implications in Health and Disease." J. Biomed. Sci. 21 (1): 77.

[9] Report of a Joint FAO/WHO Expert Consultation. 2001. "Human Vitamin and Mineral Requirements." Thailand: FAO/WHO, 53-64.

[10] Caudill, M. A. 2010. "Folate Bioavailability: Implications for Establishing Dietary Reommendations and Optimizing Status." Am. J. Clin. Nutr. 91 (5): 1455S-60S.

[11] Ulvik, A., Ueland, P. M., Fredriksen, A., Meyer, K., Vollset, S. E., Hoff, G., and Schneede, J. 2007. "Functional Inference of the Methylenetetrahydrofolate Reductase 677C > T and 1298A > C Polymorphisms from a Large-Scale Epidemiological Study." Hum. Genet.121 (1): 57-64

[12] Yila, T. A., Sasaki, S., Miyashita, C., Braimoh, T. S., Kashino, I., Kobayashi, S., Okada, E., Baba, T., Yoshioka, E., Minakami, H., Endo, T., Sengoku, K., and Kishi, R. 2012. "Effects of Maternal 5, 10-Methylenetetrahydrofolate Reductase C677T and A1298C Polymorphisms and Tobacco Smoking on Infant Birth Weight in a Japanese Population.” J. Epidemiol. 22 (2): 91-102.

[13] Obican, S. G., Finnell, R. H., Mills, J. L., Shaw, G. M., and Scialli, A. R. 2010. "Folic Acid in Early Pregnancy: A Public Health Success Story.” FASEB J. 24 (11): 4167-74.

[14] Pilsner, J. R., Hu, H., Wright, R. O., Kordas, K., Ettinger, A. S., Sa, B. N., Cantonwine, D., Lazarus, A. L., Cantoral, A., Schnaas, L., and Te, M. M. 2010. "Maternal MTHFR Genotype and Haplotype Predict Deficits in Early Cognitive Development in a Lead-Exposed Birth Cohort in Mexico City." Am. J. Clin. Nutr. 92 (1): 226-34.

[15] Bhaskar, L., Murthy, J., and Babu, G. 2011.
"Polymorphisms in Genes Involved in Folate. Metabolism and Orofacial Clefts." Arch. Oral. Biol. 56 (8): 723-37.

[16] Varga, E. A., Sturm, A. C., Misita, C. P., and Moll, S. 2005. "Homocysteine and MTHFR Mutations: Relation to Thrombosis and Coronary Artery Disease." Circulation 111 (19): e289-e93.

[17] Guéant-Rodriguez, R. M., Guéant, J. L., Debard, R., Thirion, S., Hong, L. X., Bronowicki, J. P., Namour, F., Chabi, N. W., Sanni, A., Anello, G., Bosco, P., Romano, C., Amouzou, E., Arrieta, H. R., Sánchez, B. E., Romano, A., Herbeth, B., Guilland, J. C., and Mutchinick, O. M. 2006. "Prevalence of Methylenetetrahydrofolate Reductase 677T and 1298 Cnalleles and Folate Status: A Comparative Study in Mexican, West African, and European Populations." Am. J. Clin. Nutr. 83 (3): 701-7.

[18] Dalal, A., Pradhan, M., Tiwari, D., Behari, S., Singh, U., Mallik, G. K., Das, V., and Agarwal, S. 2007. "MTHFR 677C-->T and 1298A-->C Polymorphisms: Evaluation of Maternal Genotypic Risk and Association with Level of Neural Tube Defect." Gynecol. Obstet. Invest. 63 (3): 146-50.

[19] FAO/WHO Expert Consultation. 2004. "Vitamin and Mineral Requirements in Human Nutrition." In Consultation of 2nd ed World Heal Organ, Geneva, 289-341.

[20] Patterson, D. 2008. "Folate Metabolism and the Risk of Down Syndrome.” Downs Syndr. Res. Pract. 12 (2): 93-7.

[21] Laanpere, M., Altmäe, S., Stavreus-Evers, A., Nilsson, T. K., Yngve, A., and Salumets, A. 2010. "Folate-Mediated One-Carbon Metabolism and Its Effect on Female Fertility and Pregnancy Viability.” Nutr. Rev. 68 (2): 99-113.

[22] Reutter, H., Betz, R. C., Ludwig, M., and Boemers, T. M. 2006. "MTHFR 677 TT Genotype in a Mother and Her Child with Down Syndrome, Atrioventricular Canal and Exstrophy of the Bladder: Implications of a Mutual Genetic Risk Factor?" Eur. J. Pediatr. 165 (8): 566-8.

[23] Botto, L., and Yang, Q. 2000. "5, 10-Methylenetetrahydrofolate Reductase Gene Variants and Congenital Anomalies: A HuGE Review." Am. J. Epidemiol. 151 (9): 862-77.

[24] Esfahani, S. T., Cogger, E. A, and Caudill, M. A. 2003. "Heterogeneity in the Prevalence of Methylenetetrahydrofolate Reductase Gene Polymorphisms in Women of Different Ethnic Groups." J. Am. Diet. Assoc. 103 (2): 200-7.

[25] Greenberg, J. A., Bell, S. J, Yong, G., and Yan-Hong, Y. 2011. "Folic Acid Supplementation and Pregnancy: More than Just Neural Tube Defect Prevention." Rev. Obstet. Gynecol. 4 (2): 52-9.

[26] Antony, A. C. 2007. "In Utero Physiology: Role of Folic Acid in Nutrient Delivery and Fetal Development."Am. J. Clin. Nutr. 85 (2): 598S-603S. 
[27] Chen, X., Guo, J., Lei, Y., Lu, X., Bao, Y., Wu, L., Zheng, X., Shen, Y., Wu, B.L., and Zhang, T. 2010. "Global DNA Hypomethylation Is Associated with NTD-Affected Pregnancy: A Case-Control Study." Birth Defects Res. Part A Clin. Mol. Teratol. 88 (7): 575-81.

[28] Cadenas-Benitez, N. M., Yanes-Sosa, F., Gonzalez-Meneses, A., Cerrillos, L., Acosta, D., Praena-Fernandez, J. M., Neth, O., Gomez de Terreros, I., and Ybot-Gonzalez, P. 2014. "Association of Neural Tube Defects in Children of Mothers with MTHFR 677TT Genotype and Abnormal Carbohydrate Metabolism Risk: A Case-Control Study." Genet. Mol. Res. 13 (1): 2200-7.

[29] Van der Linden, I. J. M., Afman, L. A., Heil, S. G., and Blom, H. J. 2007. "Genetic Variation in Genes of Folate Metabolism and Neural-Tube Defect Risk." Proc. Nutr. Soc. 65 (2): 204-15.

[30] Au, K. S., Ashley-Koch, A., and Northrup, H. 2011. "Epidemiologic and Genetic Aspects of Spina Bifida and Other Neural Tube Defects.” Dev. Disabil. Res. Rev. 16 (1): 6-15.

[31] Shin, M., Kucik, J. E., Siffel, C., Lu, C., Shaw, G. M., Canfield, M. A., and Correa, A. 2012. "Improved Survival among Children with Spina Bifida in the United States." J. Pediatr. 161 (6): 1132-7.

[32] Yi, Y., Lindemann, M., Colligs, A., and Snowball, C. 2011. "Economic Burden of Neural Tube Defects and Impact of Prevention with Folic Acid: A Literature Review." Eur. J. Pediatr. 170 (11): 1391-400.

[33] Pangilinan, F., Molloy, A. M., Mills, J. L., Troendle, J. F., Parle-McDermott, A., Signore, C., O'Leary, V. B., Chines, P., Seay, J. M., Geiler-Samerotte, K., Mitchell, A., Vander-Meer, J. E., Krebs, K. M., Sanchez, A., Cornman-Homonoff, J., Stone, N., Conely, M., Kirke, P. N., Shane, B., Scott, J., and Brody, L. C. 2012. "Evaluation of Common Genetic Variants in 82 Candidate Genes as Risk Factors for Neural Tube Defects." $B M C$ Med. Genet. 13: 62.

[34] Au, K. S. , Tran, P. X., Tsai, C. C., O'Byrne, M. R., Lin, J. I., Morrison, A. C., Hampson, A. W., Cirino, P., Fletcher, J. M., Ostermaier, K. K., Tyerman, G. H., Doebel, S., and Northrup, H. 2008. "Characteristics of a Spina Bifida Population Including North American Caucasian and Hispanic Individuals.” Birth Defects Res. Part A Clin. Mol. Teratol. 82 (10): 692-700.

[35] Heseker, H. 2011. "Folic Acid and Other Potential Measures in the Prevention of Neural Tube Defects." Ann. Nutr. Metab. 59 (1): 41-5.

[36] CDC.2009. "Racial/Ethnic Differences in the Birth Prevalence of Spina Bifida-United States, 1995-2005." MMWR. 57 (53): 1409-13.

[37] Lacasan, M., Blanco-mun, J., Borja-aburto, V. H., Gonzalez-alzaga, B., and Garcia-Cavazos, R. 2012.
"Effect on Risk of Anencephaly of Gene-Nutrient Interactions between Methylenetetrahydrofolate Reductase C677T Polymorphism and Maternal Folate, Vitamin B 12 and Homocysteine Profile." Public Health Nutrition 15 (8): 1419-28.

[38] Houcher, B., Bourouba, R., Djabi, F., Yilmaz, E., Eğin, Y., and Akar, N. 2009. "Polymorphisms of 5, 10-Methylenetetrahydrofolate Reductase and Cystathionine Beta-synthase Genes as a Risk Factor for Neural Tube Defects in Sétif, Algeria." Pediatr Neurosurg. 45 (6): 472-7.

[39] Boduroğlu, K., Alanay, Y., Alikaşifoğlu, M., Aktaş, D., and Tunçbilek, E. 2005. "Analysis of MTHFR 1298A>C in Addition to MTHFR 677C>T Polymorphism as a Risk Factor for Neural Tube Defects in the Turkish Population." Turk. J. Pediatr. 47 (4): 327-33.

[40] Stolk, L., Bouwland-Both, M. I., van Mil, N. H.,Verbiest, M. M., Eilers, P. H., Zhu, H., Suarez, L., Uitterlinden, A. G., and Steegers-Theunissen, R. P. 2013. "Epigenetic Profiles in Children with a Neural Tube Defect; a Case-Control Study in Two Populations." PLoS One. 8 (11): e78462.

[41] Greene, N. D. E., Stanier, P. and Copp, A. J. 2009. "Genetics of Human Neural Tube Defects.," Hum. Mol. Genet. 18 (R2): R113-R29

[42] Shookhoff, J. M, and Gallicano, G. I. 2010. “A New Perspective on Neural Tube Defects: Folic Acid and MicroRNA Misexpression.” Genesis 48 (5): 282-94.

[43] Youssef, O. I., and EL Sayed, G. M. 2012. "MTHFR 677 CT Polymorphism and the Risk of Cardiac Septal Defects: A Pilot Study." Life Sci. J. 9 (4): 4272-5.

[44] Van Beynum, I. M., den Heijer, M., Blom, H. J., and Kapusta, L. 2007. "The MTHFR 677C->T Polymorphism and the Risk of Congenital Heart Defects: A Literature Review and Meta-Analysis." QJM. 100 (12): 743-53.

[45] Huhta, J. C., and Hernandez-Robles, J. A. 2005. "Homocysteine, Folate and Congential Heart Defects." Fetal Pediatr Pathol. 24 (2): 71-9.

[46] Cai, B. Z., Gong, D. M., Liu, Y., Pan, Z. W., Xu, C. Q., Bai, Y. L., Qiao, G. F., Lu, Y. J., and Yang, B. F. 2007. "HoMocysteine Inhibits Potassium Channels in Human Atrial Myocytes." Clin. Exp. Pharmacol Physiol. 34 (9): 851-5.

[47] Herrmann, M., Taban-Shomal, O., Hübner, U., Böhm, M., Herrmann, W. 2006. "A Review of Homocysteine and Heart Failure.” Eur. J. Heart Fail 8 (6): 571-6.

[48] Zhu, W. L., Li, Y., Yan, L., Dao, J., and Li, S. 2006. "Maternal and Offspring MTHFR Gene C677T Polymorphism as Predictors of Congenital Atrial Septal Defect and Patent Ductus Arteriosus." Mol. Hum. Reprod. 12 (1): 51-4.

[49] Christensen, K. E., Zada, Y. F., Rohlicek, C. V., 
Andelfinger, G. U., Michaud, J. L., Bigras, J. L., Richter, A., Dubé, M. P., and Rozen, R. 2013. "Risk of Congenital Heart Defects Is Influenced by Genetic Variation in Folate Metabolism." Cardiol. Young. 23 (1): 89-98.

[50] Santos-Rebouças, C. B., Corrêa, J. C., Bonomo, A., Fintelman-Rodrigues, N., Moura, K. C., Rodrigues, C. S., Santos, J. M., and Pimentel, M. M. 2008. "The Impact of Folate Pathway p Polymorphisms Combined to Nutritional Deficiency as a Maternal Predisposition Factor for Down Syndrome.” Dis. Markers 25 (3): 149-57.

[51] Costa-Lima, M. A., Amorim, M. R., and Orioli, I. M. 2013. "Association of Methylenetetrahydrofolate Reductase Gene 677C > T Polymorphism and Down Syndrome." Mol. Biol. Rep. 40 (3): 2115-25.

[52] Gilbody, S., Lewis, S., and Lightfoot, T. 2007. "Methylenetetrahydrofolate Reductase (MTHFR) Genetic Polymorphisms and Psychiatric Disorders: A HuGE Review." Am. J. Epidemiol. 165 (1): 1-13.

[53] Ragunath, P. K., and Abhinand, P. A. 2013. "Systems Biological Approach to Investigate the Lack of Familial Link Between Down's Syndrome and Neural Tube Disorders." Bioinformation 9 (12): 610-6.

[54] Centers for Disease Control and Prevention. 2015. "Data and Statistics Down Syndrom Birth Defects." National Center on Birth Defects and Developmental Disabilities. Accessed June 15, 2015. http://www.cdc.gov/ncbddd/birthdefects/downsyndrome/ data.html.

[55] Hao, L., Yang, Q., and Li, Z. 2008. "Folate Status and Homocysteine Response to Folic Acid Doses and Withdrawal among Young Chinese Women in a Large-Scale Randomized Double-Blind Trial.” Am. J. Clin. Nutr. 88 (2): 448-57.

[56] Rai, A. K., Singh, S., Mehta, S., Kumar, A., Pandey, L. K., and Raman, R. "MTHFR C677T and A1298C Polymorphisms Are Risk Factors for Down 's Syndrome in Indian Mothers." J. Hum. Genet. 51 (4): 278-83.

[57] Coppedè, F., Migheli, F., and Bargagna, S. 2009. "Association of Maternal Polymorphisms in Folate Metabolizing Genes with Chromosome Damage and Risk of Down Syndrome Folate Metabolizing Genes with Chromosome Damage and Risk of Down Syndrome Offspring." Neurosci Lett. 449 (1): 15-9.

[58] Zampieri, B. L., Biselli, J. M., Goloni-Bertollo, E. M., Vannucchi , H., Carvalho, V. M., Cordeiro, J. A., and Pavarino, E. C. 2012. "Maternal Risk for Down Syndrome Is Modulated by Genes Involved in Folate Metabolism." Dis. Markers 32 (2): 73-81.

[59] Yang, M., Gong, T., Lin, X., Qi, L., Guo, Y., Cao, Z., Shen, M., and Du, Y. 2013. "Maternal Gene Polymorphisms Involved in Folate Metabolism and the Risk of Having a Down Syndrome Offspring: A
Meta-Analysis." Mutagenesis 28 (6): 661-71.

[60] Wu, X., Wang, X., Chan, Y., Jia, S., Luo, Y., and Tang, W. 2013. "Folate Metabolism Gene Polymorphisms MTHFR C677T and A1298C and Risk for Down Syndrome Offspring: A Meta-Analysis." Eur. J. Obstet. Gynecol. Reprod. Biol. 167 (2): 154-9.

[61] Coppedè, F., Grossi, E., Migheli, F., and Migliore, L. 2010. "Polymorphisms in Folate-Metabolizing Genes, Chromosome Damage, and Risk of Down Syndrome in Italian Women: Identification of Key Factors Using Artificial Neural Networks.” BMC Med. Genomics. 3: 42.

[62] Mohanty, P. K., Kapoor, S., Dubey, A. P., Pandey, S., Shah, R, Nayak, H. K., and Polipalli, S. K. 2012. "Evaluation of C677T Polymorphism of the Methylenetetrahydrofolate Reductase Gene and Its Association with Levels of Serum Homocysteine, Folate, and Vitamin B12 as Maternal Risk Factors for Down Syndrome.” Indian J. Hum. Genet. 18 (3): 285-9.

[63] Božović, I. B., Vraneković, J., Cizmarević, N. S., Mahulja-Stamenković, V., Prpić, I., and Brajenović-Milić, B. 2011. "MTHFR C677T and A1298C Polymorphisms as a Risk Factor for Congenital Heart Defects in Down Syndrome." Pediatr Int. 53 (4): 546-50.

[64] Rai, V., Yadav, U., Kumar, P., and Yadav, S. K. 2014. "Methylenetetrahydrofolate Reductase Polymorphism Is Not Risk Factor for Down Syndrome in North India." Indian J. Hum. Genet. 20 (2): 142-7.

[65] Brandalize, A. P., Bandinelli, E., Dos Santos, P. A., and Schüler-Faccini, L. 2010. "Maternal Gene Polymorphisms Involved in Folate Metabolism as Risk Factors for Down Syndrome Offspring in Southern Brazil.” Dis. Markers 29 (2): 95-101.

[66] Centers for Disease Control and Prevention. 2015. "Facts about Cleft Lip and Cleft Palate-Birth Defects." National Center on Birth Defects and Developmental Disabilities. Accessed June 15, 2015. http://www.cdc.gov/ncbddd/birthdefects/cleftlip.html.

[67] Jagomägi, T., Nikopensius, T., Krjutskov, K., Tammekivi, V., Viltrop, T., Saag, M., and Metspalu, A. 2010. "MTHFR and MSX1 Contribute to the Risk of Nonsyndromic Cleft Lip/Palate.” Eur. J. Oral. Sci. 118 (3): 213-20.

[68] Aşlar, D., Özdiler, E., Altuğ, A. T., and Taştan, H. 2013. "Determination of Methylenetetrahydrofolate Reductase (MTHFR) Gene Polymorphism in Turkish Patients with Nonsyndromic Cleft Lip and Palate." Int. J. Pediatr Otorhinolaryngol. 77 (7): 1143-6.

[69] Semiç-jusufagiç, A., Bircan, R., Çelebiler, Ö., Erdim, M., Akarsu, N., and Elçioğlu, N. H. 2012. "Association Between C677T and A1298C MTHFR Gene Polymorphism and Nonsyndromic Orofacial Clefts in the Turkish Population: A Case-Parent Study.” Turk J. Pediatr 
54 (6): 617-25

[70] Han, Y., Pan, Y., Du, Y. L., and Wang, L. 2011. "Methylenetetrahydrofolate Reductase C677T and A1298C Polymorphisms and Nonsyndromic Orofacial Clefts Susceptibility in a Southern Chinese Population.” DNA Cell Biol. 30 (12): 1063-8.

[71] Sözen, M. A., Tolarova, M. M., and Spritz, R. A. 2009. "The Common MTHFR C677T and A1298C Variants Are Not Associated with the Risk of Non-syndromic Cleft Lip/Palate in Northern Venezuela." J. Genet. Genomics. 36 (5): 283-8.

[72] Johnson, C. Y., and Little, J. 2008. "Folate Intake, Markers of Folate Status and Oral Clefts: Is the Evidence Converging?" Int. J. Epidemiol 37 (5): 1041-58.

[73] Mills, J. L., Molloy, A. M., Parle-mcdermott, A., Troendle, J. F., Brody, L. C., Conley, M. R., Cox, C., Pangilinan, F., Orr, D. J., Earley, M., McKiernan, E., Lynn, E. C., Doyle, A., Scott, J. M., and Kirke, P. N. 2009. "Folate-Related Gene Polymorphism as Risk Factors for Cleft Lip and Cleft Palate." Birth Defects Res. A. Clin. Mol. Teratol. 82 (9): 636-43.

[74] Blanton, S. H., Henry, R. R., Yuan, Q., Mulliken, J. B., Stal, S., Finnell, R. H., and Hecht, J. T. 2014. "The Folate Pathway and Nonsyndromic Cleft Lip and Palate." Birth Defects Res. A. Clin. Mol. Teratol. 91 (1): 50-60.

[75] Sahai, I., Mochida, G. H., Grabowski, E. F., Caruso, P. A. 2014. "Case 27-2014 a 10-Month-Old Boy with Microcephaly and Episodic Cyanosis.” New Engl. J. Med. 371 (9): 847-58.

[76] Mills, J. L., Druschel, C. M., Pangilinan, F., Pass, K., Cox, C., Seltzer, R. R., Conley, M. R., and Brody, L. C. 2005. "Folate-Related Genes and Omphalocele," Am. J. Med. Genet. 136 (1): 8-11.

[77] Mills, J. L., Carter, T. C., Kay , D. M., Browne, M. L., Brody, L. C., Liu, A., Romitti , P. A., Caggana, M., and Druschel, C. M. 2013. "Folate and Vitamin B12-Related Genes and Risk for Omphalocele." Hum. Genet. 131 (5): 739-46.

[78] Stonek, F., Hafner, E., Philipp, K., Hefler, L. A., Bentz, E., and Tempfer, C. B. 2007. "Methylenetetrahydrofolate Reductase C677T Polymorphism and Pregnancy Complications." Obstet Gynecol 110 (2): 363-8.

[79] Wang, X., Wu, H., and Qiu, X. 2013. "Methylenetetrahydrofolate Reductase ( MTHFR ) Gene C677T Polymorphism and Risk of Preeclampsia: An Updated Meta-Analysis Based on 51 Studies." Arch. Med. Res. 44 (3): 159-68.

[80] Nair, R. R., Khanna, A., Singh, R., and Singh, K. 2013. "Association of Maternal and Fetal MTHFR A1298C Polymorphism with the Risk of Pregnancy Loss: A Study of an Indian Population and a Meta-Analysis." Fertil Steril. 99 (5): 1311-8.
[81] Lee, H. A., Park, E. A., Cho, S. J., Kim, H. S., Kim, Y. J., Lee, H., Gwak, H. S., Kim, K. N., Chang, N., Ha, E. H., and Park, H. 2013. "Mendelian Randomization Analysis of the Effect of Maternal Homocysteine during Pregnancy, As Represented by Maternal MTHFR C677T Genotype, on Birth Weight.” J. Epidemiol. 23 (5): 371-5.

[82] Kordas, K., Ettinger, A. S., Lamadrid-Figueroa, H., Tellez-Rojo, M. M., Hérnandez-Avila, M., Hu, H., and Wright, R. O. 2009. "Methylenetetrahydrofolate Reductase (MTHFR) C677T, A1298C and G1793A Genotypes, and the Relationship between Maternal Folate Intake, Tibia Lead and Infant Size at Birth.” Br. J. Nutr. 102 (6): 907-14.

[83] Glanville, T., Yates, Z., Ovadia, L., Walker, J. J., Lucock, M., and Simpson, N. A. 2016. "Fetal Folate C677T Methylenetetrahydrofolate Reductase Gene Polymorphism and Low Birth Weight." J. Obstet. Gynaecol. 26 (1): 11-4.

[84] Cao,Y., Xu, J., Zhang, Z., Huang, X., Zhang, A., Wang, J., Zheng, Q., Fu, L., and Du, J. 2013. "Association Study between Methylenetetrahydrofolate Reductase Polymorphisms and Unexplained Recurrent Pregnancy Loss: A Meta-Analysis." Gene 514 (2): 105-11.

[85] Mtiraoui, N., Zammiti, W., Ghazouani, L., Braham, N. J., Saidi, S., Finan, R. R., Almawi, W. Y., and Mahjoub, T. 2006. "Methylenetetrahydrofolate Reductase C677T and A1298C Polymorphism and Changes in Homocysteine Concentrations in Women with Idiopathic Recurrent Pregnancy Losses." Reproduction 131 (2): 395-401.

[86] Bentley, S., Hermes, A., Phillips, D., Daoud, Y. A., and Hanna, S. 2011. "Comparative Effectiveness of a Prenatal Medical Food to Prenatal Vitamins on Hemoglobin Levels and Adverse Outcomes: A Retrospective Analysis." Clin Ther. 33 (2): 204-10.

[87] Martínez de Villarreal, L. E., Arredondo, P., Hernández, R., and Villarreal, J. Z. 2006. "Weekly Administration of Folic Acid and Epidemiology of Neural Tube Defects." Matern Child Health J. 10 (5): 397-401.

[88] Sethi, N. K., Wasterlain, A., and Harden, C. L. 2010. "Pregnancy and Epilepsy_When You're Managing Both." J. Fam. Pract. 59 (12): 675-9.

[89] Cheschier, N., and ACOG Committee on Practice Bulletins-Obstetrics. 2003. "Neural Tube Defects." Int. J. Gynaecol. Obstet. 83 (1): 123-33.

[90] Golbahar, J., Fathi, Z., and Tamadon, M. 2005. "Distribution of 5, 10-Methylenetetrahydrofolater Reductase (C667T) Polymorphism and Its Association with Red Blood Cell 5-Methyltetrahydrofolate in the Healthy Iranians." Clin. Nutr. 24 (1): 83-7.

[91] Qin, X., Li, J., Cui, Y., Liu, Z., Zhao, Z., Ge, J., Guan, D., Hu, J., Wang, Y., Zhang, F., Xu, X., Wang, X., Xu, X., Huo, Y. 2012. "MTHFR C677T and MTR A2756G 
Polymorphisms and the Homocysteine Lowering Efficacy of Different Doses of Folic Acid in Hypertensive Chinese Adults." Nutr. J. 11: 2.

[92] Crider, K. S., Zhu, J., Hao, L., Yang, Q. H., Yang, T. P., Gindler, J., Maneval, D. R., Quinlivan, E. P., Li, Z., Bailey, L. B., and Berry, R. J. 2011. "MTHFR 677C->T Genotype Is Associated with Folate and Homocysteine Concentrations in Large, Population-Based, Double-Blind Trial of Folic Acid Supplementation." Am J Clin Nutr. 93 (6): 1365-72.

[93] Powers, H. .J. 2007. "Folic Acid Under Scrutiny." Br. J. Nutr. 98 (4): 665-6.

[94] Troen, A. M., Mitchell, B., Sorensen, B., Wener, M. H., Johnston, A., Wood, B., Selhub, J., McTiernan, A., Yasui, Y., Oral, E., Potter, J. D., and Ulrich, C. M. 2006. "Unmetabolized Folic Acid in Plasma Is Associated with Reduced Natural Killer Cell Cytotoxicity among Postmenopausal Women." J. Nutr. 136 (1): 189-94.

[95] Morris, M. C., Evans, D. A., Bienias, J. L., Tangney, C. C., Hebert, L.E., Scherr, P. A., and Schneider, J. A. 2015. "Dietary Folate and Vitamin B 12 Intake and Cognitive Decline among Community-Dwelling Older Persons." Arch. Neurol. 62 (4): 641-5.

[96] Figueiredo, J. C., Grau, M. V., Haile, R. W., Sandler, R. S., Summers, R. W., Bresalier, R. S., Burke, C. A., McKeown-Eyssen, G. E., and Baron, J. A. 2009. "Folic Acid and Risk of Prostate Cancer: Results from a Randomized Clinical Trial.” J. Natl. Cancer Inst. 101 (6): 432-5.

[97] Kim, Y. 2007. "Folic Acid Fortification Folic Acid Fortification and Supplementation-Good for Some but Not So Good for Others." Nutr. Rev. 65 (11): 504-11.

[98] Mason, J. B., Dickstein, A., Jacques, P. F., Haggarty, P., Selhub, J., Dallal, G., and Rosenberg, I. H. 2007. "A Temporal Association between Folic Acid Fortification and an Increase in Colorectal Cancer Rates May Be Illuminating Important Biological Principles: A Hypothesis." Cancer Epidemiol Biomarkers Prev. 16 (7): 1325-9.

[99] Kernich, C. A. 2006. "Patient and Family Fact Sheet. Vitamin B12 Deficiency and the Nervous System." Neurologist. 12 (3):169-70.

[100] Roman, M. W., and Bembry, F. H. 2011. "L-methylfolate (Deplin $\left.{ }^{\circledR}\right)$ : A New Medical Food Therapy as Adjunctive Treatment for Depression." Issues Ment. Health Nurs. 32 (2): 142-3.

[101] Written Procedure. 2004. “Opinion of the Scientific Panel on Food Additives, Flavourings, Processing Aids and Materials in Contact with Food on a Request from the Commission Related to Calcium L-Methylfolate Question N EFSA-Q-2004-007." The EFSA Journal. 135: 1-20.

[102] EFSA Panel on Food Additives and Nutrient Sources
Added to Food (ANS). 2013. "Scientific Opinion on (6 S )-5-Methyltetrahydrofolic Acid, Glucosamine Aalt as a Source of Folate Added for Nutritional Purposes to Food Supplements." EFSA Journal 11 (10): 1-20.

[103] Pietrzik, K., Bailey, L., and Shane, B. 2010. "Folic Acid and L-5-Methyltetrahydrofolate Comparison of Clinical Pharmacokinetics and Pharmacodynamics." Clin. Pharmacokinet 49 (8): 535-48.

[104] Pentieva, K., McNulty, H., Reichert, R., Ward, M., Strain, J. J., McKillop, D. J., McPartlin, J. M., Connolly, E., Molloy, A., Krämer, K., and Scott, J. M. "The Short-Term Bioavailabilities of [6S] -5-Methyltetrahydrofolate and Folic Acid Are Equivalent in Men." J. Nutr. 134 (3): 580-5.

[105] Houghton, L. A., Sherwood, K. L., Pawlosky, R., Ito, S., and O'Connor, D. L. 2006. "[6S]-5-Methyltetrahydrofolate Is at Least as Effective as Folic Acid in Preventing a Decline in Blood Folate Concentrations During Lactation." Am. J. Clin. Nutr. 83 (4): 842-50.

[106] Lamers, Y., Prinz-Langenohl, R., Brämswig, S., and Pietrzik, K. 2006. "Red Blood Cell Folate Concentrations Increase More after Supplementation with [6S]-5-Methyltetrahydrofolate than with Folic Acid in Women of Childbearing Age." Am. J. Clin. Nutr. 84 (1): 156-61.

[107] Diefenbach, K., Trummer, D., Ebert, F., Lissy, M., Koch, M., Rohde, B., and Blode H. 2013. "EE-Drospirenone-Levomefolate Calcium Versus EE-Drospirenone + Folic Acid: Folate Status during 24 Weeks of Treatment and over 20 Weeks Following Treatment Cessation." Int. J. Womens Health. 5: 149-63.

[108] Lamers, Y., Prinz-langenohl, R., and Bra, S. 2006. "Red Blood Cell Folate Concentrations Increase More after Supplementation with [6S]-5-Methyltetrahydrofolate than with Folic Acid in Women of Childbearing Age." Am. J. Clin. Nutr. 84 (1): 156-61.

[109] Prinz-Langenohl, R., Brämswig, S., Tobolski, O., Smulders, Y. M., Smith, D. E., Finglas, P. M., and Pietrzik K. 2009. "[6S]-5-Methyltetrahydrofolate Increases Plasma Folate More Effectively than Folic Acid in Women with the Homozygous or Wild-Type 677CT Polymorphism of Methylenetetrahydrofolate Reductase." Br. J. Pharmacol. 158 (8): 2014-21.

[110] Ueland, P. M., Holm, P. I., and Hustad, S. 2005. "Betaine: A Key Modulator of One-Carbon Metabolism and Homocysteine Status.” Clin. Chem. Lab. Med. 43 (10): 1069-75.

[111] Cho, E., Zeisel, S. H., Jacques, P., Selhub, J., Dougherty, L., Colditz, G. A., and Willett, W. C. 2008. "Dietary Choline and Betaine Assessed by Food-Frequency Questionnaire in Relation to Plasma Total Homocysteine 
Concentration in the Framingham Offspring Study." Am. $J$. Clin. Nutr. 83 (4): 905-11

[112] McRae, M. P. 2013. "Betaine Supplementation Decreases Plasma Homocysteine in Healthy Adult Participants: A Meta-Analysis." J. Chiropr. Med. 12 (1): 20-5.

[113] Chiuve, S. E., Giovannucci, E. L., Hankinson, S. E., Zeisel, S. H., Dougherty, L. W., Willett, W. C., and Rimm, E. B. 2007. "The Association Between Betaine and Choline Intakes and the Plasma Concentrations of Homocysteine in Women." Am. J. Clin. Nutr. (7): 1073-81.

[114] Olthof, M. R., and Verhoef, P. 2005. "Effects of Betaine Intake on Plasma Homocysteine Concentrations and Consequences for Health." Curr. Drug Metab. 5 (1): $15-22$.

[115] Lee, J. E., Jacques, P. F., Dougherty, L., Selhub, J., Giovannucci, E., Zeisel, S. H., and Cho, E. 2010. "Are Dietary Choline and Betaine Intakes Determinants of Total Homocysteine Concentration ?"Am. J. Clin. Nutr. 91 (5): 1303-10.

[116] Diekman, E. F., De Koning, T. J., Verhoeven-Duif, N. M., Rovers, M. M., and Van-Hasselt, P. M. "Survival and Psychomotor Development with Early Betaine Treatment in Patients with Severe Methylenetetrahydrofolate
Reductase Deficiency.” JAMA Neurol. 71 (2): 188-94.

[117] Ucar, S. K., Koroğlu, O. A., Berk, O., Yalaz, M., Kültürsay, N., Blom, H. J, and Coker, M. 2010. "Titration of Betaine Therapy to Optimize Therapy in an Infant with 5,10-Methylenetetrahydrofolate Reductase Deficiency." Eur. J. Pediatr 169 (2): 241-3.

[118] Holm, P. I., Hustad, S., Ueland, P. M., Vollset, S. E., Grotmol, T., and Schneede J. 2007. "Modulation of the Homocysteine-Betaine Relationship by Methylenetetrahydrofolate Reductase 677 C->t Genotypes and B-Vitamin Status in a Large-Scale Epidemiological Study." J. Clin. Endocrinol. Metab. 92 (4): 1535-41.

[119] Centers for Disease Control and Prevention (CDC). 2010. "CDC Grand Rounds: Additional Opportunities to Prevent Neural Tube Defects with Folic Acid Fortification." MMWR Morb. Mortal. Wkly. Rep. 59 (31): 980-4.

[120] Blencowe, H., Cousens, S., Modell, B., and Lawn, J. 2010. "Folic Acid to Reduce Neonatal Mortality from Neural Tube Disorders." Int. J. Epidemiol. 39 (Suppl 1): i110-i21.

[121] Martin, D. N., Boersma, B. J., Howe, T. M., Goodman, J. E., Mechanic, L. E., Chanock, S. J., and Ambs, S., 2006. "Association of MTHFR Gene Polymorphisms with Breast Cancer Survival.” BMC Cancer 6: 257. 